\title{
MAESTRO AURÉLIO MELO: formação, mediação cultural e viagens pelo Nordeste brasileiro
}

\author{
Ednardo Monteiro Gonzaga do Monti \\ Gislene Danielle de Carvalho
}

\begin{abstract}
Resumo
Neste artigo, propõe-se uma discussão sobre a formação e trajetória do maestro Aurélio Melo e seus desdobramentos em ações de mediação cultural na região Nordeste do Brasil. São mobilizadas reflexões sobre mediação cultural de Gomes e Hansen (2016) e concepções de Bourdieu (1989, 2004, 2006) acerca dos capitais social, cultural e simbólico. As fontes documentais foram buscadas no acervo do Coral da Universidade Federal do Piaú e articuladas com a entrevista narrativa (auto)biográfica do sujeito protagonizado na pesquisa. Inicialmente, abordam-se o desenvolvimento musical e a trajetória do artista. Em seguida, são apresentados dois projetos liderados pelo maestro que ocorreram entre os anos $1993 \mathrm{e}$ 2012, nos quais foi possível perceber algumas características da sua mediação, como a formação de plateia por meio da utilização de repertório erudito e popular.
\end{abstract}

Palavras-chave: mediação cultural; música; narrativa (auto)biográfica.

\section{CONDUCTOR AURÉLIO MELO: training, cultural mediation and travel in Northeast Brazil}

\begin{abstract}
This article proposes a discussion on the educational background and career trajectory of the orchestra conductor Aurélio Melo and its unfolding in actions of cultural mediation in the Northeast region of Brazil. Reflections on cultural mediation in accord with Gomes and Hansen (2016), and conceptions of Bourdieu $(1989,2004,2006)$ concerning social, cultural, and symbolic capital are mobilized. The documentary sources were searched in the collection of the Federal University of Piauís Choir and articulated with the (auto)biographical narrative of the individual focused in the research. Initially, the musical development and the career trajectory of the artist are approached. After that, the paper presents three projects led by the conductor that occurred between years of 1993 and 2012, in which it was possible to perceive some characteristics of his mediation, such as the formation of an auditorium by means of a repertoire mixing scholarly and popular music.
\end{abstract}

Keywords: cultural mediation; music; (auto) biographical narrative.

\section{MAESTRO AURÉLIO MELO: formación y mediación cultural en el Noreste de Brasil}

\section{Resumen}

En este artículo se plantea una discusión en torno a la formación del maestro Aurélio Melo y sus desdoblamientos en acciones de mediación cultural en la región Nordeste de Brasil. Se movilizan reflexiones acerca de la mediación cultural de Gomes y Hansen (2016) y concepciones de Bourdieu (1989, 2004, 2006), respecto a los capitales social, cultural y simbólico. Las fuentes documentales se las buscaron en el acervo del Coral de la Universidad Federal de Piauí y se las articularon a la entrevista narrativa (auto)biográfica del sujeto protagonista de la investigación. Inicialmente, se abordaron el desarrollo musical y la trayectoria del artista. Luego, se presentan tres proyectos liderados por el maestro que tuvieron lugar entre los años 1993 y 2012, en los cuales se pudo señalar algunas características de su mediación, como el uso del repertorio mezclado entre el erudito y el popular.

Palabras clave: mediación cultural; música; narrativa (auto)biográfica. 


\section{INTRODUÇÃO}

Neste estudo, abordamos a formação e atuação de Raimundo Aurélio de Melo, maestro da Orquestra Sinfônica de Teresina (OST), na perspectiva da História da Educação. Sua trajetória profissional tem relevância por tratar-se de um Mediador ${ }^{1}$ cultural idealizador de vários trabalhos e projetos desenvolvidos com o Coral da Universidade Federal do Piaú, com a OST e outros diferentes grupos instrumentais e vocais, em uma constante atividade de formação de plateia no Estado do Piauí.

Justifica-se esta pesquisa pela escassez de estudos sobre a temática da mediação cultural, em especial nos âmbitos artístico e acadêmico, no estado piauiense, nos últimos dez anos, em diferentes plataformas, tais como: Banco de Teses e Dissertações da CAPES, SciELO - Biblioteca Eletrônica Científica Online, Sumários de Revistas Brasileiras, Portal de Periódicos da CAPES e sites dos programas de pós-graduação das áreas humanas e sociais do estado nordestino.

A análise desse itinerário artístico e educacional do Maestro Aurélio Melo, na região Nordeste do Brasil, à luz da História da Educação, ajuda-nos, utilizando as palavras de Nóvoa (2004, p. 10), a “[...] pensar os indivíduos como produtores de história”. O músico piauiense, seus influenciadores, seus alunos e o público que, ao longo da sua carreira cinquentenária, presenciou a realização das suas produções artísticas são os sujeitos envolvidos e entrecruzados na narrativa (auto)biográfica do Mediador.

O recorte temporal deste estudo situa-se entre os anos 1993 e 2012. Esse delineamento se justifica pelo fato de 1993 ser o ano inicial do Projeto de Recitais de Natal do Coral da Universidade Federal, e de 2012 ter sido o ano de lançamento do projeto Cantata Gonzaguiana. Com isto em mente, temos como objetivo discutir sobre a formação e trajetória do maestro Aurélio Melo e seus desdobramentos em ações de mediação cultural na região Nordeste do Brasil. Nessa perspectiva, as questões norteadoras são: que influências Aurélio Melo recebeu em sua formação que possibilitaram sua comunicação com distintos públicos? Como a sua trajetória resultou em ações e projetos de mediação entre a música e as comunidades piauienses?

As fontes mobilizadas para responder as perguntas motivadoras deste estudo foram jornais impressos e eletrônicos, programas de concerto e a entrevista narrativa (auto)biográfica realizada com o Maestro Aurélio Melo. Segundo Alberti (2015, p. 169), é pertinente a entrevista ser pensada como resíduo de ação:

[...] não apenas como relato de ações passadas, é chamar a atenção para a possibilidade de ela documentar as ações de constituição de memórias - as ações que tanto o entrevistado quanto o entrevistador pretendem desencadear ao construir o passado de uma forma e não de outra (ALBERTI, 2015, p. 169).

Juntamente com Alberti (2015) entendemos que trabalhamos com reminiscências porque não são fatos em si, mas memórias. A construção desse passado de uma forma e não de outra reside naquilo que o entrevistador escolhe perguntar e naquilo que o entrevistado prioriza ao responder, e até mesmo ao lembrar. Abrahão (2003) traz uma reflexão oportuna acerca desse contexto de pesquisa:

A pesquisa autobiográfica - Histórias de Vida, Biografias, Autobiografias, Memoriais - não obstante se utilize de diversas fontes, tais como narrativas, história oral, fotos, vídeos, filmes, diários, documentos em geral, reconhece-se dependente da memória. Esta, é o componente essencial na característica do(a)

\footnotetext{
${ }^{1}$ Neste texto, utilizaremos os termos Mediador, Maestro e Músico sempre que nos referirmos a Aurélio Melo. O termo mediador, maestro e músico com "m” minúsculo, será empregado de forma geral para citar essa função.
} 
narrador(a) com que o pesquisador trabalha para poder (re)construir elementos de análise que possam auxiliar na compreensão de determinado objeto de estudo (ABRAHÃO, 2003, p. 80).

O acervo organizado por membros do Coral da Universidade Federal do Piauí, entre os anos de 1993 e 2000, também foi de grande utilidade nessa busca, por conter informações, memórias registradas em bilhetes, fotos, recortes de jornais e memorandos. Nesse sentido, entendemos, juntamente com Pierre Nora (1993, p. 15) que esse lugar de memória existe porque geralmente não há como o homem saber sobre aquilo que será necessário lembrar. "Daí a inibição em destruir, a constituição de tudo em arquivos, a dilatação indiferenciada do campo do memorável, o inchaço hipertrófico da função da memória, ligada ao próprio sentimento de sua perda e o reforço correlato de todas as instituições de memória” (NORA, 1993, p. 15).

Essas memórias tratam do Mediador, que nasceu em Oeiras, interior do Piauí, em 1955. De acordo com Santos (2016, p. 45), Aurélio Melo iniciou seus estudos com a música por meio de um projeto chamado Bandas nas Escolas na instituição onde estudava. O estímulo encontrado na escola fez o artista procurar outros caminhos para a sua formação musical, indo frequentar o Centro de Estudos e Pesquisas Interdisciplinares (CEPI), oportunidade na qual teve como professor o Maestro Reginaldo Carvalho ${ }^{2}$. Ainda conforme Santos (2016), o músico piauiense fundou grupos musicais, trabalhou na Banda 16 de Agosto, foi regente do Coral do Vaqueiros e teve participação ativa no cenário musical teresinense entre as décadas de 1970 e 1980, quando compunha músicas premiadas em festivais e fazia apresentações diversas nos espaços culturais da cidade.

Este artigo se alinha com as concepções de Gomes e Hansen (2016) sobre a mediação cultural e sua relevância como objeto de pesquisa e reflexão, por serem esses sujeitos muitas vezes não reconhecidos ou identificados. Ou seja:

[...] as práticas de mediação cultural podem ser exercidas por um conjunto diversificado de atores, cuja presença e importância nas várias sociedades e culturas têm grande relevância, porém, nem sempre reconhecimento. [...] Tais mediadores, de enorme relevância na construção e identidades culturais de indivíduos e comunidades, geralmente não são identificados e não se identificam pela categoria de intelectual (GOMES, HANSEN, 2016, p. 8).

Como suporte teórico, utilizamos também as ideias de Pierre Bourdieu (1989; 2004) sobre capital social, cultural e simbólico, além da sua concepção sobre trajetória. O francês concebe que o desenrolar da jornada de um sujeito não acontece a esmo, isolado do espaço que frequenta. É necessário refletir sobre o entorno para chegar a uma direção mais correta nesse tipo de análise. Nesse sentido, segundo Marinho (2017), as reflexões de Bourdieu sinalizam que:

[...] as experiências de vida dos indivíduos não ocorrem no vácuo, e sim incrustadas em estruturas sociais. [...] A vida dos indivíduos é concebida como resultado da relação que estes estabelecem, a partir das condições materiais e simbólicas de existência, por meio das quais estruturam seus modos de agir e de estar no mundo, simultaneamente, como agentes de reprodução e de transformação social (MARINHO, 2017, p. 27).

Sendo assim, consideramos adequado ponderar sobre o Músico, as influências em sua formação e as ações desse sujeito que se efetivaram como mediação cultural. Ainda apoiados em uma concepção bourdiana, vale destacar a sua ideia sobre a ilusão biográfica e as críticas à

\footnotetext{
${ }^{2}$ O maestro Reginaldo Carvalho será mais bem retratado à frente, quando abordarmos as influências na formação do Mediador.
} 
impossibilidade de colocar em uma narrativa escrita a vida de uma pessoa, o que por vezes é feito apenas aparentemente de forma científica, levando-o a afirmar que a "[...] história de vida é uma dessas noções de senso comum que entraram como contrabando no universo científico" (BOURDIEU, 2006, p. 183). Isso nos ajuda a ter um critério mais consistente na interpretação da trajetória do Mediador.

Para dar contornos ao estudo, o texto está organizado por meio de três aspectos atinentes à trajetória do artista, todos voltados para a mediação cultural. O primeiro focaliza as influências que o Músico recebeu em sua formação por meio dos Maestros Reginaldo Carvalho e Emmanuel Coelho Maciel. O segundo é dedicado à formação em serviço e a seus desdobramentos na Universidade Federal do Piauí. Como terceiro ponto, constroem-se reflexões sobre os dois projetos mais significativos no seu percurso: os Concertos Pelo Sertão e a Cantata Gonzaguiana.

\section{INFLUÊNCIAS NA FORMAÇÃO DO MEDIADOR}

O Maestro Aurélio Melo não teve formação acadêmica em música (regência), mas isso não significa que ele não tenha procurado o conhecimento musical por meio de estudo e orientação de artistas que perpassaram sua trajetória. Dois desses educadores são trazidos nesta análise por terem tido significância na escolha de Aurélio Melo pela mediação cultural como uma das vias de trabalho na sua carreira. Em suas memórias, o Mediador destacou-os como pessoas que o inspiraram em sua atuação.

A primeira influência que ressaltamos é o Maestro Reginaldo Carvalho. De acordo com os estudos de Silva (2015), Reginaldo nasceu em Guarabira-PB em 1932 e faleceu em João Pessoa/PB em 2013. Chegou ao Piauí nos anos 1970, onde fundou a Escola de Música de Teresina e lecionou na Universidade Federal do Piauí.

O encontro entre o Mediador e o músico paraibano aconteceu na instituição denominada Centro de Estudos e Pesquisas Interdisciplinares (CEPI). Ferreira Filho (2009 p. 18) informa que o CEPI foi um organismo criado pelo Governo do Piauí entre os anos de 1973 e 1974, com o intuito de disponibilizar, em Teresina, uma formação artístico-cultural aos professores da rede pública de ensino.

Aurélio Melo chegou ao CEPI para as aulas do professor Reginaldo Carvalho valendo-se de algo do seu capital social, que diz respeito à rede de sociabilidade do sujeito. Por exemplo, as relações sociais podem ser úteis ao progresso do indivíduo por meio de indicações para situações de trabalho. No caso do Músico, foi dessa forma que ele chegou à sala de aula do CEPI e conheceu o educador Reginaldo Carvalho. Nas suas palavras:

Um indicava o outro. Quem me levou foi o Arimatéa ${ }^{3}$ [que] já estudava com ele e falou com o Reginaldo: - 'Oh, tem um músico muito bom na banda'. $\mathrm{O}$ Reginaldo disse: - 'Pode trazer ele'. [...] Eu me tornei o aluno predileto do Reginaldo. Primeiro foram aulas de Teoria Musical [...] ele tinha umas terminologias próprias como 'Dispositivo Quantitativo Temporal Simétrico e de Retorno Periódico': para o conceito de Compasso 8. [...] Eu passei mais ou menos uns três anos só exercitando (sob a orientação do professor Reginaldo) um método muito interessante que é do Paul Hindemit. O Reginaldo era muito rigoroso e aí era exercício, exercício, exercício, exercício, era realmente muito exercício (Aurélio Melo, entrevista, 2020).

\footnotetext{
${ }^{3}$ José de Arimatéa P. da Silva foi um dos primeiros professores da Escola de Música de Teresina juntamente com Aurélio Melo, de acordo com Silva (2020, p. 57).
} 
Esse contato com Reginaldo Carvalho foi importante também para outro tipo de capital denominado por Bourdieu (1989; 2004) como capital cultural, que diz respeito a exposição à cultura. Sendo assim, Jourdain e Naulin (2017) apontam que o referido capital representa os meios que outorgam ao indivíduo condições para que ele possa usufruir os bens e hábitos particulares à cultura erudita. $\mathrm{Na}$ prática, para o Mediador, uma parte dessa aquisição se deu em momentos de apreciação musical que eram proporcionados pelo maestro vindo do Conservatório Nacional de Canto Orfeônico. O Mediador lembra do "[...] horário só para audição. Foi lá onde eu tive a oportunidade de ouvir as primeiras sinfonias, óperas. Você chegava lá, ele apagava a luz, todo mundo se deitava. Ele explicava primeiro a música todinha, e aí você ia ouvir" (Aurélio Melo, entrevista, 2020).

Essas primeiras sinfonias apreciadas por Aurélio Melo, então em formação, foram significativas para um exercício profissional que aconteceu tempos depois com o cargo de Maestro da OST. Percebe-se que isso pode ter contribuído também para o desempenho da mediação cultural, visto que Reginaldo Carvalho, ao expor seus alunos às audições, fazia um trabalho mediador juntamente com o trabalho musical.

É possível inferir uma diferença entre a mediação exercida por Aurélio Melo e aquela realizada por Reginaldo Carvalho. O primeiro, por não ter formação acadêmica, não seria reconhecido como intelectual, fato que se adequa às considerações de Gomes e Hansen (2016). O segundo já se adapta a outro tipo de mediador, o mediador intelectual. Nessa perspectiva, as autoras mencionam que:

[...] um mesmo intelectual pode ser "criador" e "mediador"; pode ser só criador ou só "mediador"; ou pode ser "mediador" em mais de um tipo de atividade de mediação cultural, sendo seu valor conferido pelo reconhecimento de seu trabalho, quer pelo público, quer pelo próprio campo intelectual com o qual dialoga (GOMES, HANSEN, 2016, p. 22).

Assim como Reginaldo Carvalho, o outro influenciador de Aurélio Melo teve sua vida iniciada fora do estado do Piauí. Trata-se do maestro e violinista mineiro Emmanuel Coêlho Maciel (1935-2015). Ferreira Filho (2009, p. 271) esclarece que Maciel chegou a Teresina graduado em Violino pela Universidade Mineira de Artes e especializado no ensino da Música no Conservatório Nacional de Canto Orfeônico ${ }^{4}$.

A aprendizagem e vivência com o Canto Orfeônico deram ao violinista uma experiência com formação de plateia voltada para apresentações envolvendo o grande público. Nessa proposta educativa, de acordo com Monti (2015), existiam dois orfeões no Conservatório Nacional de Canto Orfeônico: o Orfeão Geral e o Artístico. O primeiro fazia apresentações didáticas com peças mais simples e acessíveis ao público infantil, e o segundo tinha o objetivo de aperfeiçoar e incentivar a apreciação musical dos estudantes do Rio de Janeiro, então Distrito Federal.

Pelo que parece, Aurélio Melo foi contagiado com o trabalho de Emmanuel Coêlho Maciel. Visto que, por meio da entrevista narrativa (auto)biográfica, o Mediador cita a importância da inspiração do trabalho do violinista em sua trajetória de mediação: "Eu acho que sempre inspirei no trabalho do Prof. Emmanuel. Eu via muito o ele fazendo com o que tinha nos bairros. Eu via aquilo dali como uma meta que de tentar formar plateia. Eu fui me inspirando um pouco nessa coisa" (Aurélio Melo, entrevista, 2020). Um dos trabalhos do músico mineiro ao qual Aurélio Melo se refere é o embrião da Orquestra Sinfônica de Teresina. O vínculo entre o violinista e o Mediador

\footnotetext{
${ }^{4}$ Projeto de educação musical desenvolvido por Heitor Villa-Lobos no Brasil, com fortes ligações com o Orphéon de origem francesa no século XIX, no qual grupos formados por alunos das instituições regulares de ensino se reuniam para cantar em apresentações públicas (MONTI, 2009). Para maiores esclarecimentos consultar Canto Orfeônico: VillaLobos e as representaçôes sociais na Era Vargas (MONTI, 2015).
} 
se deu em duas situações distintas. Em um primeiro momento, Aurélio Melo exercia um cargo de gestão na Fundação Monsenhor Chaves, quando concidentemente o músico mineiro levou uma proposta para a criação da Orquestra de Câmara na cidade:

$\mathrm{Na}$ Fundação nessa época (1993) começou um projeto encabeçado pelo Professor Emmanuel, mas, o projeto surgiu lá na Coordenação de Música da Fundação, que foi $[. .$.$] começar a prática instrumental com instrumentos de$ cordas friccionadas. Até então a Fundação só trabalhava com banda de música. Justamente nessa época da minha coordenação, pediram pra fazer um projeto e foi feito. Depois veio a sugestão de quem seria a pessoa pra ser convidada. E a sugestão que foi dada foi pra ser o professor Emmanuel Coelho Maciel. [...] A Fundação adquiriu alguns instrumentos de corda, violino, instrumentos de categoria estudantil. E o professor Emmanuel começou a dar aula na Casa da Cultura pra esses instrumentos. [...] Por isso eu sempre me inspirei no Emmanuel. [...] Com pouco aprendizado (dos alunos) ele pegava e fazia as adaptações que ele era um compositor-arranjador e fazia apresentação (Aurélio Melo, entrevista, 2020).

Concordamos com Pierre Bourdieu (1989) ao refletir sobre trajetória, no sentindo de que a vida dos sujeitos não pode ser observada de forma desatrelada de eventos que aconteceram no espaço social no qual o indivíduo está inserido. Eis um caso no qual pode ser observado esse pensamento: o Mediador, exercendo uma função de gestão, foi um agente facilitador da origem do grupo que seria o gérmen da orquestra que veio a conduzir em anos futuros.

Além do âmbito do Centro de Estudos e Pesquisas Interdisciplinares (CEPI), a formação em serviço foi outra oportunidade aproveitada pelo Músico para fortalecer o seu capital cultural. Um curso oferecido pela Universidade Federal do Piauí, com o intuito de capacitar um profissional para atender a uma demanda do Curso de Educação Artística, foi um momento de aprendizagem que resultou, para Aurélio Melo, em uma função de técnico da instituição. De que maneira essa experiência foi útil na trajetória do Músico como mediador?

\section{FORMAÇÃO EM SERVIÇO}

A música tem uma escrita própria (MONTI, 2015). A partitura é o meio de registro para a notação musical. $\mathrm{Na}$ era da tecnologia, partituras complexas e simples podem ser feitas por softwares no computador e até por aplicativos no celular. Porém, na década de 1980, não era assim. Existia uma classe de profissionais nessa época para transcrever as partituras manualmente, os musicógrafos.

Sendo assim, Aurélio Melo foi musicógrafo na Universidade Federal do Piauí, e essa foi uma experiência significativa na sua trajetória. Antes de ser contratado, participou de um curso oferecido pela própria instituição com o intuito de formar um profissional que seria contratado ao final da formação:

Eu fui o primeiro musicógrafo da universidade e copiava a bico de pena [...] eu era muito criterioso. [...] Era eu copiando e analisando a partitura. Então isso foi outro aprendizado. Eu pegava muitos arranjos do prof. Emmanuel, do Reginaldo Carvalho e de outros, Guerra Peixe que eu tinha a oportunidade de escrever e às vezes perdia muito tempo na cópia, porque eu passava um tempão só aqui olhando, analisando. Ia lá no instrumento e olhava: como o cara fez esse negócio aqui? Tudo isso foi enriquecendo esse meu conhecimento que vinha da prática do Paul Hindemit (Aurélio Melo, entrevista, 2020). 
Maestro Aurélio Melo procurou alinhar conhecimentos anteriores à nova função que começou a exercer na universidade. Isso fortaleceu o seu capital cultural, porque, a cada partitura transcrita, analisava harmonicamente os arranjos, tentando extrair os caminhos escolhidos pelos compositores e arranjadores, comparando-os com sua própria forma de trabalhar a harmonia musical.

Em 1998, Aurélio Melo lançou um livro intitulado Arranjos Corais pela editora da Universidade Federal do Piauí. Na introdução, justificou a relevância da sua obra pela dificuldade, na época, de encontrar partituras corais com arranjos vocais para música popular. Ele pretendia minimizar essa lacuna:

Não é difícil encontramos partituras de clássicos da música vocal, porque são muitas publicações nesse particular. Entretanto, quando se trata da música popular, a coisa se torna mais complicada uma vez que são raras as publicações, mesmo havendo uma forte produção de arranjos nesse gênero, através do excelente trabalho dos regentes arranjadores que se dedicam a adaptar clássicos da nossa música popular para coro a quatro vozes. O que temos são pouquíssimas partituras, geralmente ilegíveis, de um arranjador aqui ou outro acolá conseguidas através de reproduções xerográficas, em algum encontro de corais ou painéis de regência (MELO, 1998, p. 5).

Como nenhuma ação do indivíduo fica isolada em sua trajetória, essa função exercida por Aurélio Melo contribuiu para ressaltar outro capital, o simbólico. Esse capital retrata o respeito social angariado pelo sujeito. De acordo com Bourdieu (2004, p. 160), "[...] o capital simbólico não é outra coisa senão o capital econômico ou cultural quando conhecido e reconhecido". Entendemos que, no prefácio do livro Arranjos Corais, há uma dessas evidências - o maestro Emmanuel Coêlho Maciel faz considerações sobre a caminhada de Aurélio:

Sempre atento e observador, pouco a pouco ele transformava seu ofício de musicógrafo em fator de crescimento musical, reforçando a máxima comum que diz 'qualquer observação meticulosa, científica, resulta em aprendizagem'. E aí, com o passar do tempo, a exemplo de E. Humperdinck (festejado compositor de óperas alemão, que aprendeu a técnica do Leitmotiv, criada por Richard Wagner, copiando as partes musicais da ópera 'Parsifal') Aurélio Melo aprimorou-se na arte de compor arranjos para coro e instrumento de um modo geral (MACIEL, 1998, p. ?).

Encontramos imagens que são remanências da atuação do Mediador como musicógrafo. Podemos ver o cuidado com o trabalho manual, desde a simetria das figuras musicais à letra da música abaixo das notas. O ano em que foi feita, como podemos ver ao lado da assinatura, é 1987: 
Figura 1: Trecho de partitura transcrita por Aurélio Melo

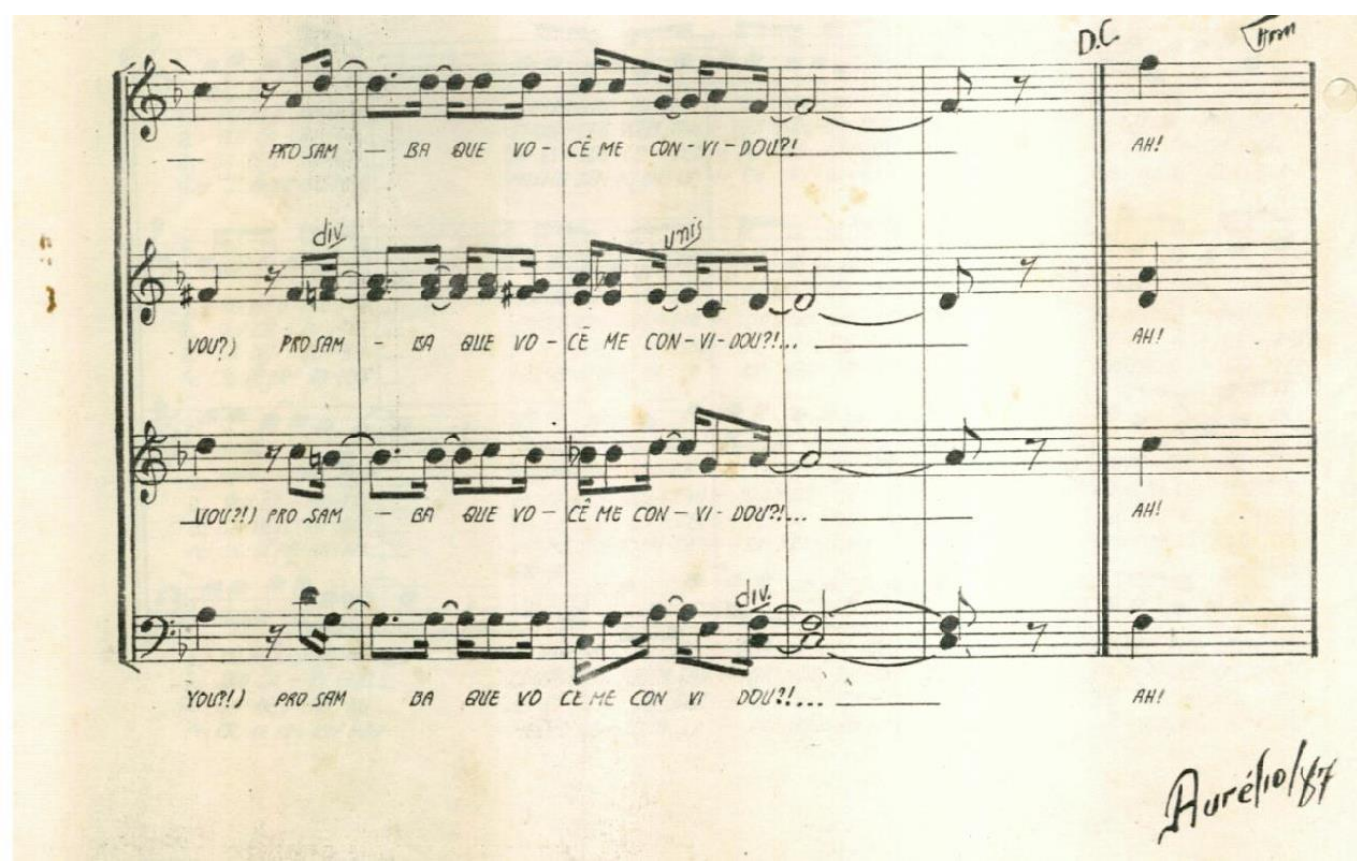

Fonte: Acervo do Coral da UFPI.

Na Figura 1, a música Samba do Arnesto, do compositor Adoniran Barbosa, está fragmentada em um arranjo coral. O trabalho do Mediador como musicógrafo pode aí ser visto. Podemos ainda dispor dessa imagem para assinalar outro pensamento pertinente acerca de como a pesquisa histórica nos apresenta muitos caminhos. Observando as marginálias das partituras, Monti (2015) nos traz uma ponderação significativa:

[...] a música acompanha a História e os registros dessa expressão artística é um suporte para memória. As partituras guardam e retratam em suas páginas, pela musicografia, as paisagens sonoras de experiências e manifestações de um indivíduo, de uma comunidade, de um povo, de uma nação; os selos dos seus editores apontam os vínculos dos compositores e suas instituições, as marginálias indicam as datas dos ensaios e apresentações de quem as manusearam (MONTI, 2015, p. 211).

A assinatura de Aurélio Melo no ano de 1987, no pleno exercício da profissão de musicógrafo na Universidade Federal do Piauí, e o lançamento do livro de arranjos corais em 1998 reforçam o conceito de trajetória. O livro Arranjos Corais é, em parte, fruto de uma aprendizagem que começou na década de 1970, no Centro de Estudos Interdisciplinares.

Aurélio Melo comparava as partituras que escrevia, como essa de 1987, com os seus estudos pessoais de harmonia, quase dez anos depois. O Mediador já se encontrava em outra posição com condições de fazer um livro contendo seus próprios arranjos. Esse lançamento bibliográfico converge com a terceira seção do artigo, espaço no qual tratamos dos Projetos da Mediação.

Algumas escolhas de Aurélio Melo na mediação cultural foram possíveis com a regência da Orquestra Sinfônica de Teresina, como é o caso de dois projetos: os Concertos pelo Sertão com a Orquestra Sinfônica de Teresina e a Cantata Gonzaguiana. Como esses projetos contribuíram para a formação de plateia? Em que locais, além do estado piauiense, esses projetos tiveram circulação? 


\section{PROJETOS MUSICAIS EDUCATIVOS DE MEDIAÇÃO CULTURAL}

Entendemos que o trabalho de mediação cultural de Aurélio Melo, na sua trajetória cinquentenária, aconteceu em vários projetos. Dentre outros, ressaltamos dois que, segundo a entrevista narrativa (auto)biográfica com o Mediador, foram dos mais importantes para sua trajetória (MELO, 2020). Nessa perspectiva, interpretamos como essas iniciativas tiveram repercussão na cidade de Teresina, no Sertão do Nordeste, e no Distrito Federal - Brasília. Sendo assim, os investimentos artísticos escolhidos para esta seção foram: os Concertos pelo Sertão com a Orquestra Sinfônica de Teresina e a Cantata Gonzaguiana.

Durante 30 anos, o Mediador esteve à frente do Coral da Universidade, com destaque para o projeto Recitais de Natal, iniciado em 1993, que tinha como público-alvo as periferias da capital. No final desse tempo de trabalho, Aurélio Melo assumiu também a regência da Orquestra Sinfônica de Teresina, sucedendo o Maestro Emmanuel Coêlho Maciel. O Músico recebeu uma Orquestra de Câmara e conseguiu, com apoio de instituições como os Correios, realizar a compra de instrumentos que posteriormente contribuíram para a mudança do status para Orquestra Filarmônica e, em seguida, para Orquestra Sinfônica. No formato sinfônico, foi possível concorrer a um edital da Petrobrás, idealizado pelo compositor e produtor Gilvan Santos ${ }^{5}$; e, no período de 12 a 20 de novembro de 2010, concretizaram-se as apresentações do intitulado Concertos pelo Sertão - com a Orquestra Sinfônica de Teresina.

\section{Figura 2: Cartaz oficial da turnê Concertos pelo Sertão}

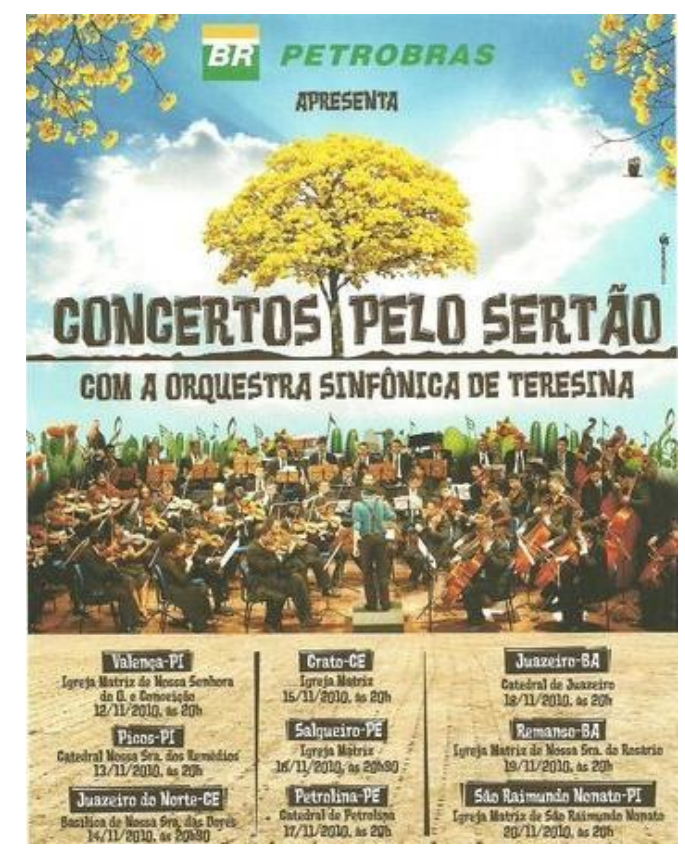

Fonte: Sousa (2010).

\footnotetext{
${ }^{5}$ Gilvan Santos, compositor e produtor musical teresinense, teve a iniciativa de propor a Aurélio Melo a inscrição no edital da Petrobrás depois de assistir a um concerto da Orquestra Sinfônica de Teresina na Catedral da cidade. Tem dois álbuns com música autoral: Terra de Ninguém e Encantador. Na época da elaboração do Projeto Concertos pelo Sertão com a Orquestra Sinfônica de Teresina, era aluno de Políticas Públicas. Teve a carreira abreviada por um Acidente Vascular Cerebral, cuja sequela foi a perda da voz, depois do término do projeto. (MAGALHÃES, SILVA, 2010, p. 3).
} 
O cartaz oficial da turnê traz informações como as cidades contempladas. Houve nove apresentações distribuídas por quatro estados do Nordeste - Piauí, Ceará, Pernambuco e Bahia. Uma viagem pelo semiárido com uma orquestra sinfônica tocando um repertório erudito e popular tem uma significância peculiar. Muitas pessoas viram e ouviram aqueles instrumentos pela primeira vez. Aurélio Melo fala das escolhas do repertório:

Fizemos um repertório inteligente onde colocamos um pouco de música erudita, alguns movimentos de sinfonia e colocamos uma música que eu imaginava que seria mais próxima do povo. Uma música que motivasse a autoestima das pessoas que iriam assistir. Então colocamos um dos maiores compositores nordestinos, amado por todos - o Luiz Gonzaga. Colocamos também alguma coisa de música piauiense. [...] No projeto nós já colocamos que as apresentações seriam nas igrejas, sendo assim também colocamos no repertório música religiosa, que tem tudo a ver com a realidade cultural dessas pessoas. Então colocamos aqueles benditos cantando nas novenas. [...] Percebemos que as pessoas ouviam Beethoven, Luiz Gonzaga e os benditos da mesma forma (Aurélio Melo, entrevista, 2020).

A preocupação do Mediador em mesclar o erudito e o popular no repertório dos concertos foi estratégica na medida em que ampliou as possibilidades de apreciação do público e facilitou a mediação, criando um ambiente de identificação cultural dos presentes ao executar os benditos e a música de Luiz Gonzaga. Um livro foi elaborado com depoimentos e imagens dos concertos. Além disso, foi produzido um documentário com o registro das apresentações e relatos de quem presenciou, nas igrejas lotadas, a disposição e sonoridade dos músicos da Orquestra Sinfônica de Teresina. De acordo com Magalhães e Silva (2010, p. 3), o edital da Petrobrás proporcionou a ampliação do espaço de conhecimento do trabalho da orquestra, assim como a experiência popular, minimizando a "[...] carência de contato do sertanejo com a música sinfônica, ausente das programações das emissoras de rádio".

O livro Petrobras apresenta: Concertos pelo Sertão - com a Orquestra Sinfônica de Teresina (2010), um relatório que é fruto impresso do projeto, traz uma sinopse da história da OST; o roteiro das cidades, com um histórico de cada uma; o nome de cada igreja contemplada, com comentários sobre os concertos; além de depoimentos de algumas pessoas de cada região que estiveram presentes nas apresentações. Fotografias ilustram a brochura, mostrando os músicos no momento das execuções e as igrejas lotadas de uma audiência atenta.

Havia nos concertos um padrão: começavam com o Hino Nacional; depois, era a vez das peças eruditas; em seguida, iniciava-se o repertório nordestino; e o espetáculo era encerrado com músicas religiosas, com a participação emocionada dos espectadores. Aurélio Melo crê que esse trabalho consolidou a identidade da Orquestra Sinfônica de Teresina, o norte de sua trajetória (MELO, 2020). Na época dessa turnê, o Músico estava mais ou menos há dois anos à frente do grupo.

Eu tinha assumido a orquestra estava com uns dois anos, mais ou menos. [...] $\mathrm{O}$ patrocínio dos Correios foi uma coisa muito importante porque a orquestra teve condições de assumir determinadas funções como uma grande orquestra. [...] Esse projeto foi muito importante porque eu não tinha experiência com orquestra, eu vinha de uma escola de música popular, sempre buscando uma linha que determinasse uma característica da música piauiense. [...] Então de repente eu estava na orquestra sinfônica. E pensava o que a orquestra vai fazer? Qual vai ser a cara? [...] Nesse projeto a orquestra adquiriu personalidade, que fez com que nós chegássemos até hoje conhecida, simpática, apreciada e amada pelo povo dessa região. Então eu digo aqui e confirmo, isso foi solidificado através 
desse projeto Concertos pelo Sertão. Ele me deu a certeza que o caminho seria esse (Aurélio Melo, entrevista, 2020).

Essa certeza registrada na fala do Mediador possibilitou as condições para um investimento posterior: trabalhar a música de Luiz Gonzaga em um concerto exclusivamente dedicado a esse compositor. Tal escolha se mostrou significativa, porque repercutiu no processo de mediação cultural. Muitas pessoas assistiram ao concerto não só em Teresina, como em outras cidades do Brasil; e o espetáculo culminou com a apresentação da orquestra piauiense numa das homenagens oficiais como tributo ao centenário de Luiz Gonzaga no Senado Federal.

O terceiro projeto, chamado Cantata Gonzaguiana, foi vislumbrado por Aurélio Melo dois anos antes do centenário do Rei do Baião. Nessa feita, o Músico considerou arranjar para a orquestra alguns sucessos de Luiz Gonzaga e colocar na voz imitativa de João Cláudio Moreno 6 . O humorista aceitou o convite e, além de cantar, cerzia o espetáculo com pequenos contos da vida do sanfoneiro (MELO, 2020).

Figura 3: Imagem do DVD Cantata Gonzaguiana

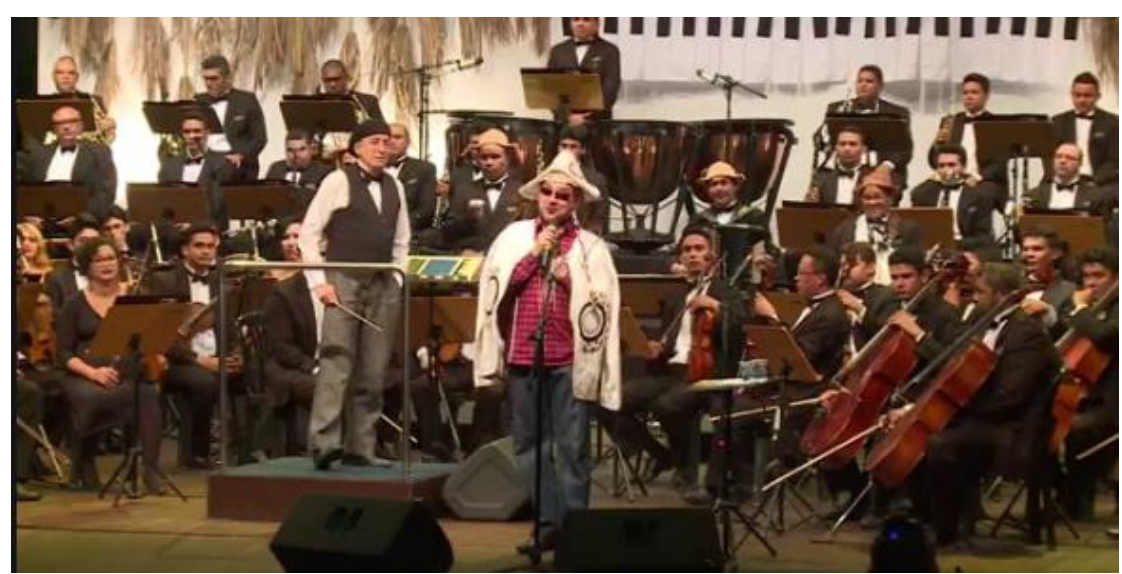

Fonte: Gravação (2020).

Essa imagem da gravação do DVD da Cantata Gonzaguiana, no Theatro 4 de Setembro ${ }^{7}$, é um registro do projeto que foi feito depois de várias viagens pelo Brasil. Podemos ver à frente da Orquestra Sinfônica do Piauí o Maestro Aurélio Melo e o artista João Cláudio Moreno, na posição de solista, contando algumas das histórias que entrelaçavam as peças musicais. A gravação do DVD foi possível por meio de um convênio entre a Secretaria de Cultura do Estado do Piauí - SECULT e a Associação dos Amigos da Orquestra Sinfônica de Teresina, conforme consta no Diário Oficial do Estado do Piauí:

\footnotetext{
${ }^{6}$ João Cláudio Moreno é um humorista piauiense, nascido na cidade de Piripiri em 1967. Em sua carreira de 30 anos completados em 2019, dentre outras vivências, trabalhou com Chico Anísio como redator, gravou com Hermeto Pascoal na década de 1990 e participou de um curta metragem sobre João Cabral de Melo Neto (MORENO, 2019, p. 4).

${ }^{7}$ O Theatro 4 de Setembro fica localizado na Praça Pedro II, no centro da capital piauiense, configurando-se como o principal teatro da cidade. Foi construído em 1889 pelo então presidente da província do Piauí, Dr. Theophilo dos Santos, em resposta a um pedido de um grupo de senhoras e da primeira-dama do estado à época (OLIVEIRA, 2010).
} 
DOI: $10.12957 /$ teias.2022.53536

Figura 4: Extrato de convênio publicado no Diário Oficial do Estado do Piauí

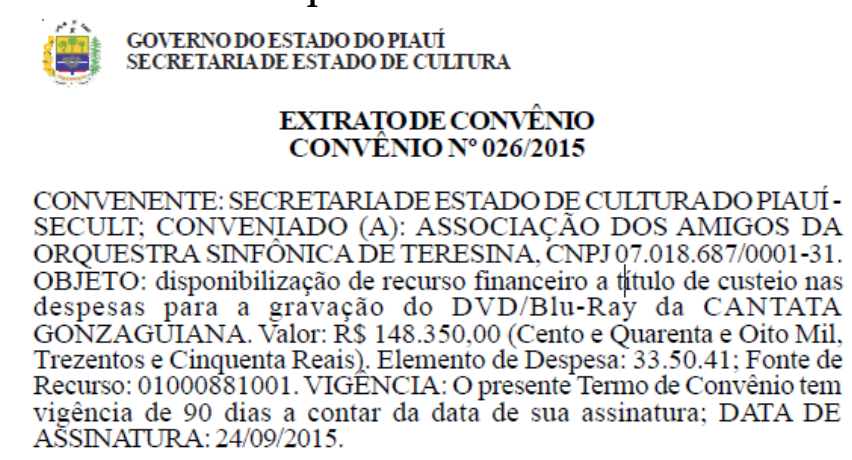

\section{FÁBIONÚNEZNOVO}

Secretário da Secretaria de Estado de Cultura do Piauí

Fonte: Piauí (2015, p. 20).

Entendemos que uma das características do trabalho de Maestro Aurélio Melo é a intenção de colocar nos concertos música erudita e popular, assim como fez com o Coral da Universidade Federal do Piauí. Na Cantata, esse objetivo foi procurado ao se colocar a orquestra, que tem uma composição erudita, à disposição de um repertório popular, sem descaracterizar a harmonia criada pelo conhecido e consagrado sanfoneiro Luiz Gonzaga.

É pertinente refletir sobre como a Cantata teve apresentações por várias cidades brasileiras. As obras de Luiz Gonzaga, possivelmente mobilizam a plateia, pois seu repertório é consagrado pelo gosto popular, principalmente nordestino, por retratar o Nordeste com temáticas pertinentes à sua cultura. Thompson (2002) assevera que cultura é o padrão "[...] de significados incorporados nas formas simbólicas, que inclui ações, manifestações verbais e objetos significativos de vários tipos, em virtude dos quais os indivíduos comunicam-se entre si e partilham experiências, concepções e crenças" (THOMPSON, 2002, p. 176).

A identificação com as letras de Luiz Gonzaga; o apelo instrumental dessas harmonias e ritmos ampliados do som da sanfona, da zabumba e do triângulo para uma orquestra sinfônica; e a imitação da voz de Luiz feita por um artista habilidoso e carismático resultaram em uma combinação que conquistou o público nos concertos realizados. João Cláudio Moreno, em uma entrevista para a Gazeta de Notícias (2019), resumiu em poucas palavras a turnê da Cantata: "A Cantata Gonzaguiana com a Orquestra Sinfônica de Teresina [...] nós andamos em 42 cidades do Brasil inteiro [...] com 80 músicos se apresentando com [...] cenário [...] eu participei disso em 2012 no ano do centenário de Luiz Gonzaga, inclusive no Congresso Nacional” (MORENO, 2019).

A apresentação no Congresso Nacional, segundo Aurélio Melo (2020), foi a mais política da Orquestra Sinfônica do Piauí. Outras apresentações são indicadas por ele como muito significativas - e, para utilizar os termos bourdianos, podemos apontá-las como validações do capital simbólico da orquestra e do próprio Aurélio Melo.

Nós fomos convidados para fazer a homenagem do Brasil ao Luiz Gonzaga, feita pelo Congresso Nacional. Brasília tem uma orquestra sinfônica que está anos-luz à frente da Orquestra Sinfônica de Teresina, mas não foi nem cogitada. [...] Foi muito interessante fazer a Cantata Gonzaguiana no Salão Nobre do Congresso Nacional, gravado pela TV Senado que depois passou um mês reproduzindo. [...] Tocamos também em Palmas para quase cinco mil pessoas na Praça do Girassol na Feira Internacional do Livro, umas principais do Brasil. [...] Mas o que eu considero muito importante artisticamente foi a orquestra ser convidada para encerrar as festividades do Luiz Gonzaga no Santuário do Rei do Baião em Exu. 
[...] Pernambuco também tem uma orquestra que está muito tempo na frente da nossa sinfônica. [...] Então tudo isso aconteceu porque pensamos um pouco antes dos outros, quando começou o centenário nós já estávamos com a estreia da Cantata Gonzaguiana marcada (Aurélio Melo, entrevista, 2020).

O Músico reconhece que outras orquestras seriam mais sofisticadas musicalmente e mais bem preparadas estruturalmente; entretanto, o diferencial da Orquestra Sinfônica de Teresina de representar a cultura nordestina foi significativo para a escolha da OST na homenagem oficial a Luiz Gonzaga no Planalto Central e no Museu do Rei do Baião em Exu-BA.

Essas experiências de Aurélio Melo foram fruto de uma concepção de que esse era o melhor caminho para construir uma ponte entre a música e a comunidade. Nos dois projetos aqui abordados, constatamos uma preocupação em equilibrar o erudito e o popular em concertos didáticos, mas nem por isso sem o apelo de conquistar o público para a música feita com um grupo sinfônico, para o canto coral e para uma identidade cultural nordestina.

\section{CONSIDERAÇÕES FINAIS}

Enfim, duas influências foram relevantes para que Aurélio Melo, em sua formação, entendesse como se comunicar com públicos distintos e escolhesse direcionar a sua ação principalmente às comunidades carentes. Podemos citar o Maestro Reginaldo Carvalho com quem Aurélio Melo teve aulas de Teoria Musical, Harmonia e Apreciação, e o Maestro Emmanuel Coêlho Maciel que foi uma inspiração ao reger a Orquestra de Câmara de Teresina deixando como legado o grupo que Aurélio Melo elevou à categoria de Orquestra Sinfônica e manteve o cuidado de continuar fazendo concertos acessíveis ao público da periferia.

A trajetória de Aurélio Melo resultou em ações e projetos de mediação entre a música e as comunidades piauienses. No presente estudo destacamos dois momentos da carreira do Maestro, os Concertos Pelo Sertão, que aconteceram durante o ano de 2010, contemplando nove cidades do Nordeste com apresentações gratuitas da Orquestra Sinfônica de Teresina, executando um programa que mesclava peças eruditas e populares e a Cantata Gonzaguiana que teve estreia em 2012, viajou por várias cidades brasileiras com um repertório exclusivo de músicas de Luiz Gonzaga em um tratamento sinfônico acrescidos à formação da orquestra os instrumentos triângulo, sanfona e zabumba.

\section{REFERÊNCIAS}

ABRAHÃO, Maria Helena Menna Barreto. Memória, narrativas e pesquisa autobiográfica. Revista História da Educação, Pelotas, v. 7, n. 14, p. 79-95, set. 2003.

ALBERTI, Verena. Histórias dentro da História. In: PINSKY, Carla Bassanezi (org.). Fontes históricas. São Paulo: Contexto, 2015. p. 155-202.

BOURDIEU, Pierre. A ilusão biográfica. In: AMADO, Janaína; FERREIRA, Marieta de Moraes. Usos e abusos da história oral. 8. ed. Rio de Janeiro: Editora FGV, 2006. p. 183-191.

BOURDIEU, Pierre. Coisas ditas. Tradução de Cássia R. da Silveira e Denise Moreno Pegorim. São Paulo: Brasiliense, 2004.

BOURDIEU, Pierre. O poder simbólico. Tradução de Fernando Tomaz. Rio de Janeiro: Bertrand Brasil, 1989. 
FERREIRA FILHO, João Valter. História e memória da Educação Musical no Piauí: das primeiras iniciativas à universidade. 2009. 226 f. Dissertação (Mestrado em Educação) - Programa de PósGraduação em Educação, Universidade Federal do Piauí, Teresina, 2009.

GOMES, Ângela de Castro; HANSEN, Patrícia Santos. Apresentação: intelectuais, mediação cultural e projetos políticos: uma introdução para delimitação do objeto de estudo. In: GOMES, Ângela de Castro; HANSEN, Patricia Santos (org.). Intelectuais mediadores: práticas culturais e ação política. Rio de Janeiro: Civilização Brasileira, 2016. p. 5-11.

GRAVAÇÃO do DVD Cantata Gonzaguiana: João Cláudio Moreno e OST. [S. 1.: s. n.], 13 out. 2015. 1 vídeo (3 min 3 s). Disponível em https://www.youtube.com/watch?v=9d0ZmocK_6k. Acesso em 16 jul. 2020.

JOURDAIN, Anne; NAULIN, Sidonie. A teoria de Pierre Bourdieu e seus usos sociológicos. Petrópolis, Rio de Janeiro: Vozes, 2017. (Sociologia: pontos de referência).

MACIEL, Emmanuel Coêlho. Prefácio. In: MELO, Raimundo Aurélio. Arranjos Corais. Teresina: Edufpi, 1998. p. 7-7.

MAGALHÃES, Laerte; SILVA, Iane Carolina. Petrobras apresenta: Concertos Pelo Sertão: com a Orquestra Sinfônica de Teresina. Teresina: Associação dos Amigos da Orquestra Sinfônica de Teresina, 2010.

MARINHO, Marco Antonio Couto. Trajetórias de Vida: um conceito em construção. Revista do Instituto de Ciências Humanas, Belo Horizonte, v. 15, n. 17, p. 25-49, nov. 2017.

MELO, Aurélio. Arranjos corais. Teresina, Piauí: EDUFPI, 1998.

MONTI, Ednardo Monteiro Gonzaga do. Canto Orfeônico: Villa-Lobos e as representações sociais da Era Vargas. 20009. 177 f. Dissertação (Mestrado) - Curso de Mestrado em Educação, Centro de Teologia e Humanidades, Universidade Católica de Petrópolis, Petrópolis, Rio de Janeiro, 2009.

MONTI, Ednardo Monteiro Gonzaga do. Polifonias Políticas, Identitárias e Pedagógicas: VillaLobos no Instituto de Educação do Rio de Janeiro na Era Vargas. 2015. 264 f. Tese (Doutorado em História da Educação) - Programa de Pós-Graduação em Educação, Universidade Federal do Rio de Janeiro, Rio de Janeiro, 2015.

MORENO, João Claudio. João Cláudio Moreno: 30 anos de humor e amadurecimento. [Entrevista cedida a] Waldelúcio Barbosa. Gazeta de Notícias, Juazeiro do Norte, p. 4-5, jan. 2019.

NORA, Pierre. Entre memória e história: a problemática dos lugares: a problemática dos lugares. Projeto História: Programa de Estudos Pós-Graduados de História, São Paulo, v. 10, n. 10, p. 7 28, dez. 1993.

NÓVOA, Antônio. Por que a História da Educação. In: STEPHANOU, Maria; BASTOS, Maria Helena Camara (orgs.). Histórias e memórias da Educação no Brasil: volume I, séculos XVII XVIII. Petrópolis, Rio de Janeiro: Vozes, 2004. p. 9-12.

OLIVEIRA, Thayse. Teatro 4 de Setembro faz 116 anos: é obra inacabada. 180graus, [s. 1.], 04 set. 2010. Disponível em https://180graus.com/cultura/teatro-4-de-setembro-faz-116-anos-e-obrainacabada-357752. Acesso em 23 jul. 2020.

PIAUÍ. Licitações e Contratos. Convênio n. 026/2015, de 14 de setembro de 2015. Diário Oficial do Governo do Piauí: n. 214, Teresina, ano 84, p. 20, 28 set. 2015.

SANTOS, Raimundo Nonato Lima dos. Praticando espaços, entre acordes, letras e máscaras: história, memória e sociabilidades em espaços culturais de Teresina nas décadas de 1980 e 1990. 
2016. 378 f. Tese (Doutorado em História) - Programa de Pós-Graduação em História, Universidade Federal de Pernambuco, Recife, 2016.

SILVA, Juniel Pereira da. Casa de Sons - Escola de Música de Teresina (1981-1991): sujeitos e práticas educativas entre salas e palcos. 2020. 113 f. Dissertação (Mestrado em Educação) Programa de Pós-Graduação em Educação, Universidade Federal do Piauí, Teresina, 2020.

SILVA, Vladimir Alexandro Pereira. Entrevista com o compositor Reginaldo Carvalho. Debates: Cadernos do Programa de Pós-Graduação em Música, Rio de Janeiro, v. 15, p. 33-48, nov. 2015.

THOMPSON, John B. Ideologia e cultura moderna: teoria social crítica na era dos meios de comunicação de massa. Petrópolis, Rio de Janeiro: Vozes, 2002.

Submetido em agosto de 2020

Aprovado em fevereiro de 2022

\section{Informações do/a autor/a}

Ednardo Monteiro Gonzaga do Monti

Universidade Federal do Piauí

E-mail: ednardo@ufpi.edu.br

ORCID: https://orcid.org/0000-0003-3513-3316

Link Lattes: http://lattes.cnpq.br/1728209127429787

Gislene Danielle de Carvalho

Universidade Federal do Piauí

E-mail: gislenedanielle@,ufpi.edu.br

ORCID: https://orcid.org/0000-0002-7860-7721

Link Lattes: http://lattes.cnpq.br/3773566924034786 